\title{
Field evaluation of $(E)$-2-hexenal efficacy for behavioral manipulation of egg parasitoids in soybean
}

\author{
Cecília Rodrigues Vieira • Maria Carolina Blassioli -Moraes • Miguel Borges • \\ Carmen Silvia Soares Pires • Edison Ryoiti Sujii • Raúl Alberto Laumann
}

Received: 29 January 2014/Accepted: 9 June 2014/Published online: 1 July 2014

(C) International Organization for Biological Control (IOBC) 2014

\begin{abstract}
We studied the influence of synthetic (E)2-hexenal on the abundance of Telenominae aiming to attract parasitoids and enhance stink bug egg parasitism in treated areas. We conducted experiments in 2006, 2007 and 2008 soybean seasons with two shortterm (one week) and one long-term (seven weeks) experiment, respectively. We evaluated the abundance of parasitoids with yellow sticky traps and estimated the incidence and intensity of parasitism with sentinel eggs of Euschistus heros Fabricius (Hemiptera: Pentatomidae) or with tulle bags, enclosing laboratory pregnant E. heros as an egg source. In short-term experiments, there was increased abundance of
\end{abstract}

Handling Editor: Stefano Colazza

C. R. Vieira $(\bowtie)$ · E. R. Sujii · R. A. Laumann

Programa de Pós-Graduação em Ecologia, Universidade de Brasília, Campus Universitário Darcy Ribeiro, Asa

Norte, Brasília, DF 70.910-900, Brazil

e-mail: ceciliavieira@me.com

C. R. Vieira - M. C. Blassioli -Moraes .

M. Borges - C. S. S. Pires - E. R. Sujii ·

R. A. Laumann $(\square)$

Embrapa Recursos Genéticos e Biotecnologia, Parque

Estação Biológica, W5 Norte, Asa Norte, Brasília,

DF 70.770-917, Brazil

e-mail: raul.laumann@embrapa.br

Present Address:

C. R. Vieira

Department of Biology, Utah State University, 5305 Old

Main Hill, BNR 121, Logan, UT 84322, USA
Trissolcus spp. (Hymenoptera: Platygastridae: Telenominae) in treated areas, associated with greater intensity of parasitism. In long-term experiments, treatment with $(E)$-2-hexenal did not influence the abundance of Telenominae or parasitism levels, but increased egg predation. Applications of (E)-2-hexenal can be used to increase recruitment of Trissolcus spp. in the early flowering stages of soybean and also to attract other natural enemies, but do not increase egg parasitism.

Keywords Pentatomidae $\cdot$ Telenominae $\cdot$ Green leaf volatile $\cdot$ Herbivore-induced plant volatile $\cdot$ Natural enemy

\section{Introduction}

Volatiles produced by hosts and plants, especially herbivore-induced plant volatiles (HIPVs), play an important role in the foraging behavior of parasitoids and may influence their search for hosts (Price et al. 1980; Vet and Dicke 1992; Borges and Aldrich 1994). The use of these cues to manipulate the distribution and abundance of natural enemies offers important prospects for biological control and integrated pest management (Hare 2011; Vinson et al. 1998). Volatiles have the potential to attract or retain parasitoids in a particular area, thereby increasing host mortality rates and altering the relationships between hosts and natural enemies (Vet and Dicke 1992). 
Soybean is attacked by several herbivores and stink bugs (Hemiptera: Pentatomidae) are some of the most damaging (Panizzi 1997). In Brazil, the cosmopolitan egg parasitoids Trissolcus spp. and Telenomus spp. (Hymenoptera: Platygastridae: Telenominae) occur naturally, and their high fecundity and densitydependent parasitism (Corrêa-Ferreira and Moscardi 1996; Laumann et al. 2008, Meats and Pando 2002) make them key regulators of stink bug populations (Corrêa-Ferreira and Moscardi 1995; Medeiros et al. 1998). Therefore, biological control services of parasitoids are a valuable tool to reduce the use of pesticides in agriculture and contribute to the preservation of natural resources (Corrêa-Ferreira and Moscardi 1996; Straub et al. 2008).

Borges et al. (1999) reported the attraction of Telenomus podisi (Ashmead) in field conditions by traps baited with sex pheromone of the brown stink bug, Euschistus heros Fabricius (Hemiptera: Pentatomidae). The attraction of $T$. podisi by the sex pheromone of E. heros, as well as the use of this pheromone in host recognition, was confirmed afterward in laboratory experiments (Borges et al. 1999; Silva et al. 2006). Laboratory studies also showed that females of Trissolcus basalis (Wollaston) are attracted to volatiles of the stink bug Nezara viridula (Linnaeus) (Hemiptera: Pentatomidae) that are produced by virgin males and females in a pre-oviposition situation, and also to plant synomones induced by feeding and oviposition of this stink bug species (Colazza et al. 1999, 2004). Similar results were obtained for Trissolcus brochymenae Ashmead, when stimulated by volatiles from males, females and nymphs of the stink bug Murgantia histrionica Hahn (Hemiptera: Pentatomidae) (Conti et al. 2003). (E)-2-hexenal, one of the major components of metathoracic glands secretions of stink bugs (Aldrich 1988; Aldrich et al. 1995; Baker et al. 1987; Pareja et al. 2007) and also a volatile produced by stink bug host plants (e.g. soybean, bean and maize, Michereff et al. 2011; Moraes et al. 2008b), attracted $T$. podisi and T. basalis in laboratory experiments (Laumann et al. 2009; Pires et al. 2001). In short (seven days) field studies, $(E)$-2-hexenal was efficient in attracting released adults of Trissolcus spp. and in increasing parasitism on stink bug eggs during the flowering stage of soybean (Peres 2004).

Herein, we tested the influence of $(E)$-2-hexenal on the abundance of free-range Telenomus spp. and Trissolcus spp. on soybean crops. We evaluate whether application of $(E)$-2-hexenal in the field increases the attraction and retention of natural enemies in treated areas. We expected an increase in the abundance of parasitoids in treated areas and, consequently, higher occurrence and intensity of parasitism in stink bug eggs, which would provide evidence of the compound effectiveness. In addition, we compared different methods of assessing the effects of semiochemicals on natural enemies in field experiments. We found that (E)-2-hexenal works as a long-distance cue to attract Trissolcus spp. during the early reproductive stage of soybean. Further, we discovered that $(E)$-2-hexenal apparently attracts other natural enemies of stink bugs, as evidenced by increased egg predation. Finally, we found that parasitism is seemingly more influenced by egg density or maybe other cues than by the application of $(E)$-2-hexenal.

\section{Materials and methods}

Study areas

We conducted experiments during three consecutive growing seasons in two areas in the Distrito Federal, central Brazil. In the first (2006) and second (2007) seasons, the experimental area was located on a private farm at Colônia Agrícola Lamarão $\left(15^{\circ} 58^{\prime} 94^{\prime \prime} \mathrm{S}\right.$, $47^{\circ} 30^{\prime} 16^{\prime \prime} \mathrm{W}$ ). The soybean monoculture field (cv MSOY 6101) had a total cultivated area of $\sim 55$ ha, surrounded by riparian vegetation and an intercrop area (sorghum). In the first and second seasons sampling took place during one week (short-term experiment), always in the flowering stage of soybean plants (R2, Ritchie et al. 1988). To account for the temporal variation in the influence of $(E)$-2-hexenal on the abundance of parasitoids, we conducted a long-term experiment in the third season (2008) and sampling took place during seven weeks at Embrapa Recursos Genéticos e Biotecnologia experimental station, Brazil $\left(15^{\circ} 43^{\prime} 50^{\prime \prime} \mathrm{S}, 47^{\circ} 53^{\prime} 59^{\prime \prime} \mathrm{W}\right)$, throughout the entire reproductive cycle of soybean. A riparian forest and other small crops of papaya, castor oil plant, sunflower and cotton surrounded the soybean area.

Insects

We obtained all the eggs and adults of the brown stink bug, E. heros, used in field experiments from a 
laboratory colony maintained at Embrapa Recursos Genéticos e Biotecnologia. We followed the rearing procedures described by several authors (Silva et al. 2006; Costa et al. 1998; Laumann et al. 2011).

\section{Impregnation of rubber septa with $(E)$-2-hexenal}

We impregnated red rubber septa with $(E)$-2-hexenal the day before they were placed in the field. Initially, we diluted pure $(E)$-2-hexenal (Sigma-Aldrich, United States) in $97 \%$-pentane (Sigma-Aldrich, Germany) to achieve concentrations of $5 \mathrm{mg}$ per septa (H1). We treated rubber septa referring to $\mathrm{H} 1$ applying an aliquot of $250 \mu \mathrm{l}$ from $20 \mathrm{mg} \mathrm{ml}^{-1}$ stock solution of (E)-2-hexenal. For control plots, we applied $250 \mu \mathrm{l}$ of pure $n$-pentane in each septum. The selection of dosage used in the field was in accordance with previous works (Peres 2004) and with experiments to evaluate the releasing rate of the compound conducted in the laboratory (Vieira et al., unpublished data). We stored groups of septa dependent on treatment in aluminum foil and placed them at $-20{ }^{\circ} \mathrm{C}$ separately packed in plastic freezer bags to be used the next day. The septa were transported to the field in polystyrene foam boxes and kept on temperature below $10{ }^{\circ} \mathrm{C}$ with ice packs.

\section{Short-term experiments}

\section{Parasitoid attraction}

We evaluated the effect of synthetic $(E)$-2-hexenal on the attraction of adult parasitoids using yellow sticky traps (Biotrap ${ }^{\circledR}$, BioControle Métodos de Controle de Pragas Ltda.) and rubber septa baited with the compound. For the first season (2006), we marked two $900 \mathrm{~m}$ transects, separated $150 \mathrm{~m}$ apart from each other, in the soybean field. Along each transect, we distributed six equidistant stakes (every $150 \mathrm{~m}$ ), which served as support to rubber septa attached by wires, treated with $n$-pentane (control) or (E)-2hexenal $5 \mathrm{mg}$ (H1 treatment). We randomly assigned treatments to each stake and also placed in each one, below the rubber septa, a $24.0 \mathrm{~cm} \times 30.0 \mathrm{~cm}$ yellow sticky trap to capture adult parasitoids (Fig. 1a). For the second season (2007), we used the same design, also with control and $\mathrm{H} 1$ treatment, except that both $900 \mathrm{~m}$ transects had ten stakes each and were $100 \mathrm{~m}$ apart from each other (Fig. 1c). In both seasons, we kept traps and treatments in the field for seven days, along the flowering stage of soybean plants (R2, Ritchie et al. 1988). For all seasons, we placed rubber septa approximately $1.20 \mathrm{~m}$ above ground. We wrapped all traps in plastic film and stored them in refrigerator so that the insects could be identified at a later date.

\section{Egg parasitism rates}

To investigate the effect of $(E)$-2-hexenal on parasitism, we assessed the incidence (presence or absence) and intensity (proportion of parasitized eggs) of parasitism by the distribution of E. heros sentinel eggs or enclosed pregnant females around treated rubber septa. The sentinel eggs consisted of $3.0 \mathrm{~cm} \times 3.0 \mathrm{~cm}$ cardboard strips containing eggs glued with Arabic gum.

In the first season, we established two $900 \mathrm{~m}$ transects in a neighbor soybean crop, adjacent to the lines traced for the experiment with sticky traps. Along each transect, we distributed ten equidistant (every $100 \mathrm{~m}$ ) stakes, which served as a support to rubber septa filled with $n$-pentane (control) or $(E)$-2hexenal $5 \mathrm{mg}(\mathrm{H} 1)$ and attached by wires. We assigned treatments randomly to each stake. Then, we sorted four soybean plants, one in each cardinal direction and $1 \mathrm{~m}$ far from each stake (Fig. 1b), and attached one cardboard with sentinel eggs ( $\mathrm{N}=50$ eggs per card) to each plant, with color tape. Previously, we covered all sentinel egg cardboards with $\sim 2 \mathrm{~mm}$ thick tulle, which allowed free passage of parasitoids and avoided predator's access to the eggs (e.g. other stink bugs and beetles). We exposed eggs in the field for five days.

During the second season, we worked in two $50 \mathrm{~m} \times 50 \mathrm{~m}$ plots, each with four rubber septa at the vertices, treated with $n$-pentane (control) and $(E)$-2hexenal $5 \mathrm{mg}(\mathrm{H} 1)$. Plots were adjacent to the soybean field where adult parasitoids were sampled in that season. To simulate a natural infestation and detect parasitism rates, we enclosed nine plants with silk-net bags ( $\sim 2 \mathrm{~mm}$ mesh) along both plot diagonals spaced 10-15 $\mathrm{m}$ from each other and infested each bag with fifteen pregnant females of E. heros ( $\mathrm{N}=15$ females per bag) as an egg source (Fig. 1d). The silk-net bag worked like a cage and was capable to hold the stink bugs inside and to allow free movement of parasitoids. We closed the bags on both extremities with cotton strings and kept them in the field for five days. 
Short-term experiment (2006)

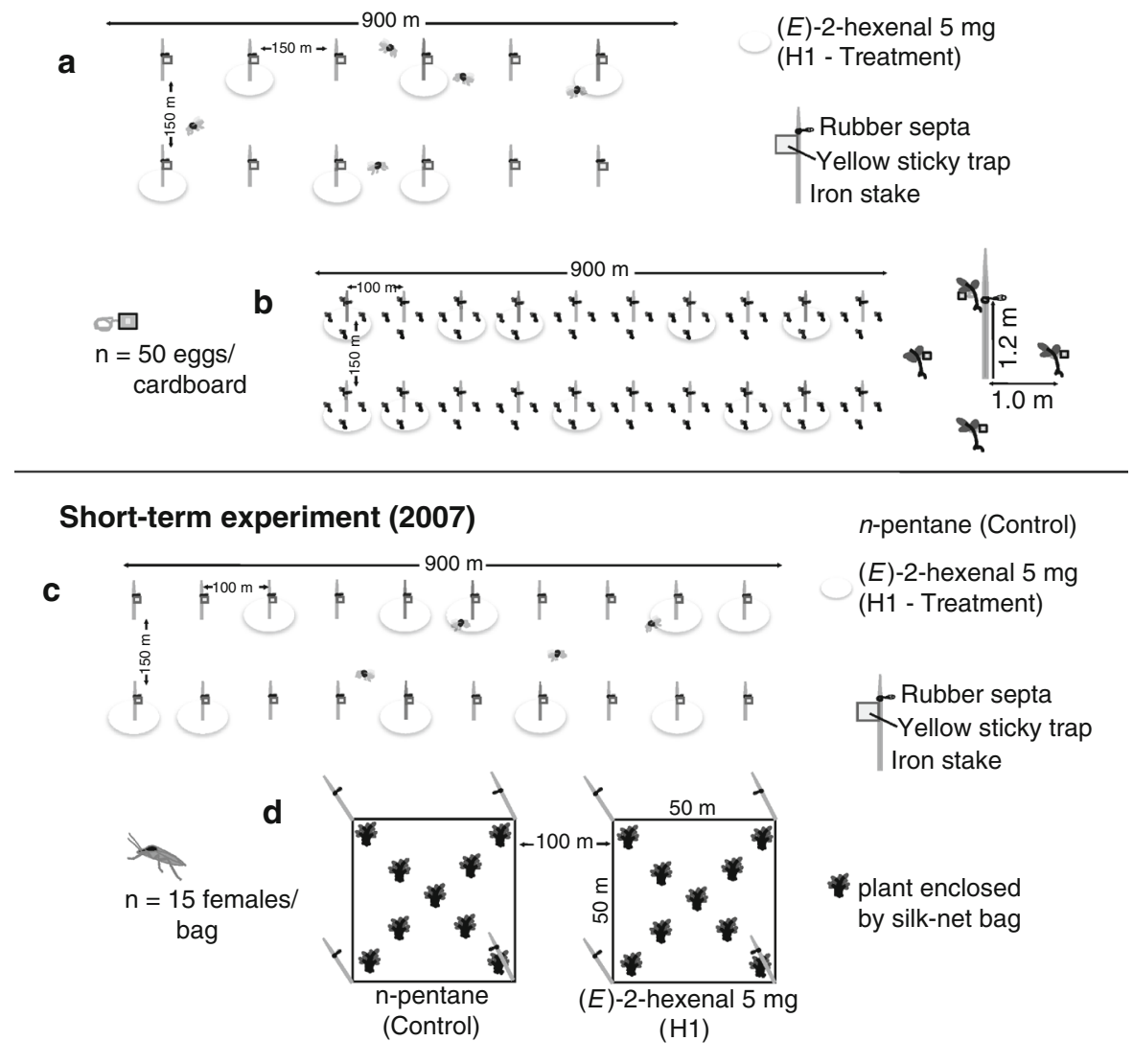

$n$-pentane (Control)

(E)-2-hexenal $5 \mathrm{mg}$

Yellow sticky trap

ntake

\section{Long-term experiment (2008)}

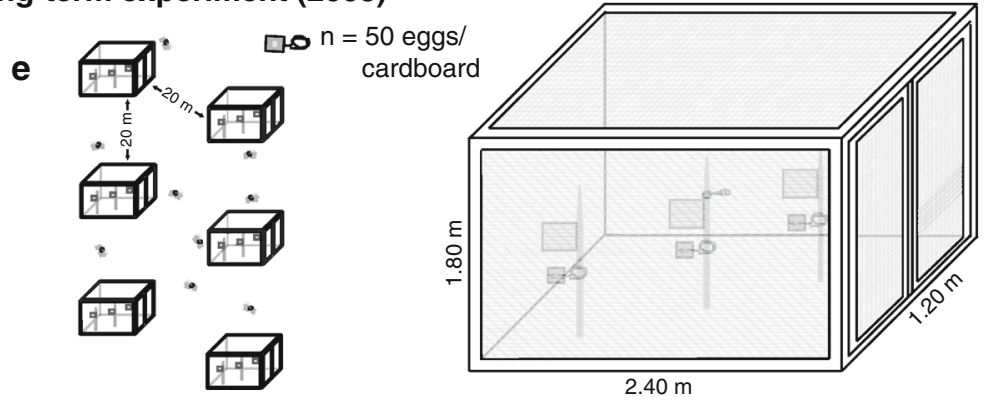

Fig. 1 Experimental design for assessing effects of $(E)-2$ hexenal upon the abundance of adult parasitoid and parasitism rates on Euschistus heros eggs. Short-term experiments: 2006 and 2007; long-term experiment: 2008. a Adult parasitoids sampling with yellow sticky traps; b estimation of egg parasitism rates with sentinel eggs in cardboards; c estimation

Afterward, we removed the bags with plants from the field and transported them to the laboratory where we individualized egg masses deposited by stink bugs on plants. of parasitism rates upon egg masses laid by E. heros females inside tulle bags; $\mathbf{d}$ adult parasitoids sampling with yellow sticky traps; e adult parasitoids sampling with yellow sticky traps and estimation of egg parasitism rates with sentinel eggs in cardboards within cages

We placed all eggs in separated plastic containers with lids and maintained them in a room with controlled environmental conditions (LD 14:10 h, 26.0 $\pm 1^{\circ} \mathrm{C}$ and $65 \pm 10 \% \mathrm{RH})$. We verified parasitism by the 
emergence of parasitoids or by dissecting eggs and recording the presence of pupae and immature stages, when parasitoids did not complete their development. To count adult parasitoids and parasitized eggs, and to identify emerged parasitoids, we used a Zeiss SV6 stereomicroscope. We identified and quantified parasitoids (Telenominae) to the lowest possible taxonomic level following the dichotomous key developed by Dr. Marta Loiácono (Museo de La Plata, Argentina). We also recorded the number of inviable eggs while observing egg masses recovered from the field in the first season. We recognized eggs attacked by sucking predators as being empty or dry, with the exterior surface intact, and by feeding holes made by predators; eggs attacked by chewing predators had a shredded exterior surface still attached to the cardboard, without the top cap of the egg (Tillman 2010). Some eggs were lost to the action of rain: they were quantified as missing and were not considered in the analysis.

\section{Long-term experiment}

\section{Parasitoid attraction}

In the third season (2008), we conducted a long-term experiment to test the effects of $(E)$-2-hexenal applications on parasitoid population dynamics, and also to check the effects of long-term application on parasitoids recruitment and parasitism levels. We randomly distributed six cages of about $5.2 \mathrm{~m}^{3}(\mathrm{~W}: 2.4 \mathrm{~m}, \mathrm{H}: 1.8 \mathrm{~m}$, D: $1.2 \mathrm{~m}$ ), apart from each other at least $20 \mathrm{~m}$ on a 0.5 ha soybean area (cvMSOY 6101) at the beginning of the reproductive stage of plants. Cages were kept in the field until the soybean physiological maturity (from flowering to physiological maturity, R1-R7, Ritchie et al. 1988). We infested each cage with fifteen E. heros stink bugs to achieve the density of two stink bugs per meter (control action level, Embrapa 2010). We covered cages with $\sim 4 \mathrm{~mm}$ mesh durable polyester to keep stink bugs inside and to allow free movement of parasitoids. We randomly assigned treatments to three cages with (E)-2-hexenal (H1) and three control cages ( $n$-pentane). Along one diagonal of each cage we placed three evenly spaced iron stakes. To assess parasitoid abundance, we attached by wire one $12.0 \mathrm{~cm} \times$ $15.0 \mathrm{~cm}$ yellow sticky trap to each stake and a rubber septum to the central stake (Fig. 1e). We exposed the adhesive surface of sticky traps during three days for each week of the soybean reproductive cycle, for a total of seven weeks, removing traps after the third day. We replaced traps and rubber septa weekly, four days after trap removal, until the end of the soybean cycle (physiological maturity of plants).

\section{Egg parasitism rates}

To estimate parasitism indices, we placed three cardboard strips with sentinel eggs out weekly $(\mathrm{N}=$ 50 eggs per card, Fig. 1e) around the central septum in each cage. We conducted the experiment during the same period as the adult parasitoid sampling in this season. We exposed sentinel eggs in the field for three days and replaced them four days after removal, coinciding with the replacement of rubber septa. Subsequently, after exposure in the field, we collected the sentinel eggs and verified parasitism and predation as previously described for the short-term experiments.

\section{Statistical analyses}

\section{Parasitoid attraction}

To assess the effects of $(E)$-2-hexenal on the abundance of parasitoids sampled with sticky traps in transects, during the first and second seasons, we used a logistic regression (Quinn and Keough 2002). In this analysis, the grouping variable was the presence or absence of (E)-2-hexenal, whereas the abundance of Telenomus spp., Trissolcus spp. and all other parasitoids were used as predictors. Used in this fashion, logistic regression is equivalent to discriminant analysis (DA), where a combination of predictors is used to predict group membership. However, because our predictor variables are discrete, not continuous variables, the logistic regression is by far superior, being more flexible then the DA; predictors are not assumed to be normally distributed, linearly related, or with homoscedasticity (Tabachnick and Fidell 2013). To check the adequacy of the full model, we compared it to an intercept-only (null) model with the Pearson $\chi^{2}$ statistic and we used a manual forward selection approach to determine predictor importance by adding variables to the null model and assessing model improvement with a significance $\chi^{2}$ test of the reduction in scaled deviance (Crawley 2012).

For the third sampling season, we used a generalized linear mixed model (GLMM) with a Poisson error distribution and a log link function (Demidenko 2013; 
Galecki and Burzykowski 2013) implemented with the package lme4 (Bates et al. 2013) to assess differences between treatment with $(E)$-2-hexenal and control cages in the total abundance of Telenominae sampled with sticky traps, throughout the soybean reproductive cycle. We pooled the abundance of all Telenominae, since Telenomus spp. were captured three times as often, whereas Trissolcus spp. were rare. In this model, we used two fixed-effect parameters, treatment with (E)-2-hexenal (with levels control vs. (E)-2-hexenal) and weeks (1-7), and cage as a random effect (Zuur et al. 2009). We assessed the significance of the fixed factors and their interaction by comparing the full model with simpler models, sequentially dropping terms and using significance tests $\left(\chi^{2}\right)$ of the reduction in scaled deviance (Crawley 2012).

\section{Egg parasitism rates}

We assessed the effect of (E)-2-hexenal upon the incidence (presence or absence) of parasitized eggs in cardboards using a generalized linear model (GLM) specifying errors with binomial distribution and logit link function (Crawley 2012). To assess the effect of (E)-2-hexenal upon the intensity (proportion) of egg parasitism, we used a GLMM with a binomial error distribution and logit link function (Demidenko 2013; Galecki and Burzykowski 2013), implemented with the package lme4 (Bates et al. 2013). Because predation was prominent on sentinel eggs, we also tested the effect of $(E)$-2-hexenal upon the intensity of egg predation. The model incorporated a fixed-effect parameter (with levels control vs. (E)-2-hexenal) and random effects specifying the nested effect of cardboards within stake in the first season, within bag in the second season and within cage by week in the third season (Zuur et al. 2009). We performed all statistical analysis in R 3.0.2 (R Development Core Team 2013) and used the significance level of $5 \%$ for hypothesis tests.

\section{Results}

Parasitoid attraction

From the total adult parasitoids recorded with sticky traps by season $\left(\mathrm{N}_{2006}=397, \quad \mathrm{~N}_{2007}=316\right.$, $\left.\mathrm{N}_{2008}=204\right)$, Telenominae represented $29.47,44.62$ and $33.82 \%$, respectively. The main Telenominae species were $T$. podisi and $T$. basalis. The logistic regression analysis showed a significant effect of $(E)$ 2-hexenal on the abundance of parasitoids $\left(\chi^{2}=11.25, d f=3, P=0.01\right)$ during the short-term experiments, with higher abundance on treated areas (2006: control $1.83 \pm 0.75$, treatment $4.50 \pm 2.35$; 2007: control $3.60 \pm 1.90$, treatment $4.30 \pm 2.26$; values correspond to mean \pm SE abundance of parasitoids per sticky trap). The model selection indicated higher abundance of Trissolcus spp. in traps from $(E)$ 2-hexenal treated areas in both seasons $\left(\chi^{2}=10.33\right.$, $d f=1, P<0.01$, Fig. $2 \mathrm{a}-\mathrm{b}$ ), while the abundance of Telenomus spp. $\left(\chi^{2}=0.11, d f=1, P=0.74\right.$, Fig. 2 $\mathrm{c}-\mathrm{d})$ and the remaindered parasitoids $\left(\chi^{2}=0.78\right.$, $d f=1, P=0.38$, Fig. 2 e-f) were not affected by treatment. The effect of $(E)$-2-hexenal on the abundance of Trissolcus spp. was independent of season, i.e., there was no interaction between treatment and year $\left(\chi^{2}=0.03, d f=1, P=0.87\right)$.

For the long-term experiment (third season, 2008), the GLMM analysis indicated no significant effect of the interaction between treatment with $(E)$-2-hexenal and week $\left(\chi^{2}=0.21, d f=1, P=0.65\right)$ or of the treatment with $(E)$-2-hexenal $\left(\chi^{2}=0.01, d f=1\right.$, $P=0.90)$ on the abundance of Telenominae parasitoids captured with sticky traps in cages (Fig. 3a). Nevertheless, the variation of the abundance of Telenominae along the soybean reproductive stage (weeks) was significant $\left(\chi^{2}=9.19, \quad d f=1\right.$, $P<0.002)$, with an overall increase in the abundance through time (Fig. 3a).

\section{Egg parasitism rates}

In the first short-term experiment (2006), of the 4,000 eggs (80 sentinel eggs cardboards) placed in the field, $35.03 \%$ were eaten and $19.80 \%$ were lost. Telenominae parasitized $7.30 \%$ of the remaining 1,807 eggs ( $3.30 \%$ of the total placed in the field). The GLM indicated no significant effect of treatment with $(E)$-2hexenal on the incidence of parasitism in sentinel eggs $(z=1.55, P=0.12)$. However, the GLMM indicated a significant effect of treatment with $(E)$-2-hexenal on the intensity of parasitized eggs $(z=-4.10$, $P<0.01$; control: $1.26 \pm 3.34$, treatment: $2.44 \pm$ 2.97; mean parasitized eggs by treatment) and on the intensity of egg predation $(z=2.80, P=0.05$, 
Fig. 2 Boxplots of the abundance of (a-b) Trissolcus spp., (c-d) Telenomus spp. and (e-f) other parasitoids captured with yellow sticky traps in short-term experiments in 2006 and 2007 and by treatment (control: $n$-pentane, $\mathrm{H} 1$ : (E)-2-hexenal). The horizontal line in each box is the median, boxes define the hinge $(25-75 \%$ quartiles, the dashed line extends up to 1.5 times the hinge or to the maximum or minimum values), points outside the intervals are represented as dots. Significant differences at the 0.05 level are indicated by an asterisk
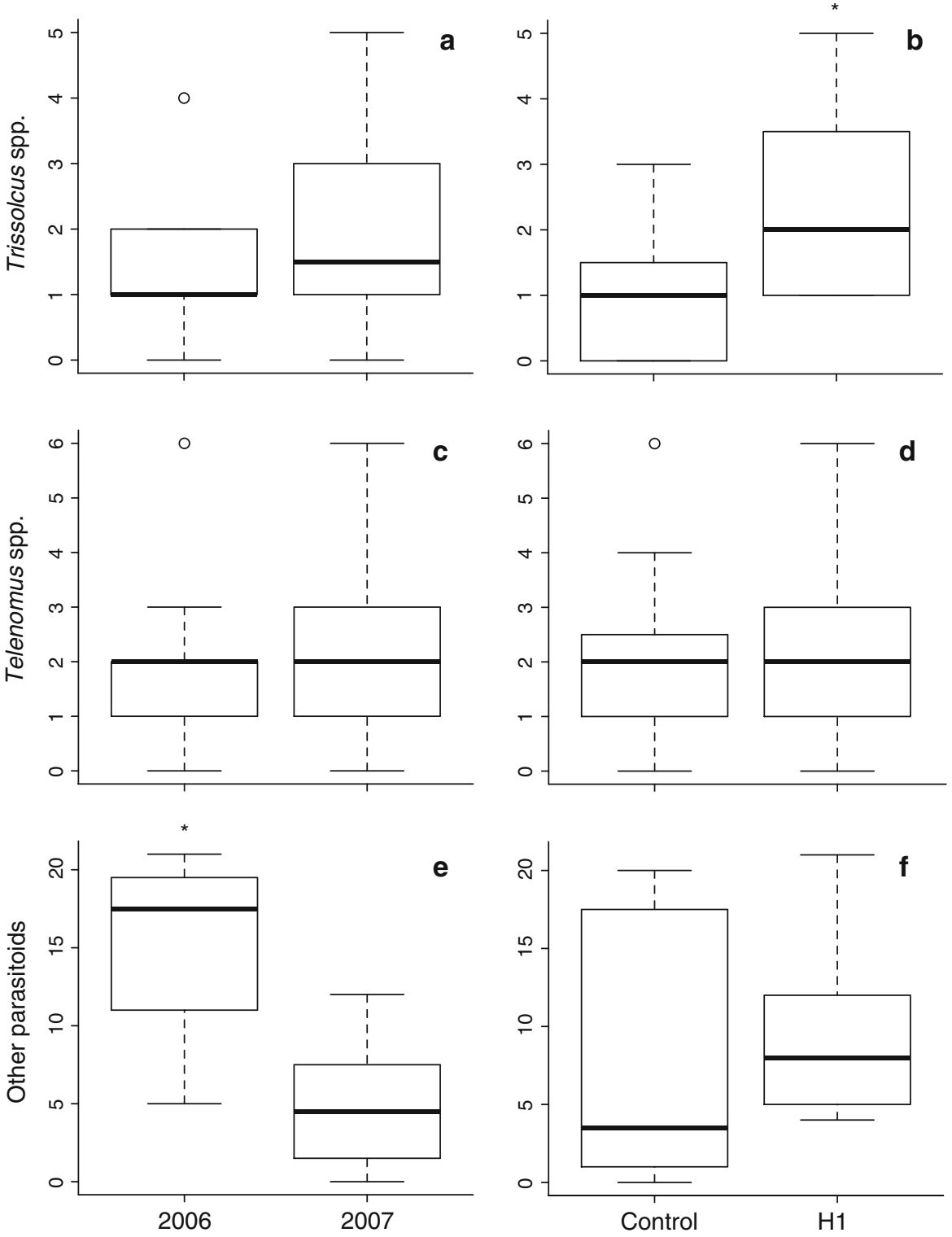

control: $20.57 \pm 24.41$, treatment: $18.92 \pm 23.75$; mean preyed eggs by treatment).

During the second short-term experiment (2007), from the total amount of egg masses deposited on soybean plants enclosed by bags $\left(\mathrm{N}_{\text {egg masses }}=130\right.$, $\left.\mathrm{N}_{\text {eggs }}=1,254\right), 40.2 \%$ were in the control plot and $59.8 \%$ in the H1 plot. Overall, $4.44 \%$ of the 1,148 eggs that were not eaten $(8.45 \%)$ were parasitized. The GLM indicated no significant effect of $(E)-2-$ hexenal on the incidence of parasitism $(z=1.83$, $P=0.07$ ), while the GLMM indicated a significant effect of $(E)$-2-hexenal on the intensity of parasitism $(z=-2.27, P=0.02$; control: $0.25 \pm 1.61$, treatment: $0.50 \pm 1.57$; mean parasitized eggs by treatment) and no significant effect on the intensity of egg predation $(z=0.22, P=0.82)$.

Of the 6,300 stink bug eggs distributed in the field during the long-term experiment, $33.63 \%$ hatched out when returned from the field, $18.17 \%$ were parasitized by Telenominae, $18.84 \%$ were preyed, $16.51 \%$ did not hatch, and $12.84 \%$ were lost due to the action of rain. The most common and potential predators observed were lady beetles, grasshoppers, crickets and other stink bugs, e.g., Geocoris spp. (Hemiptera: 

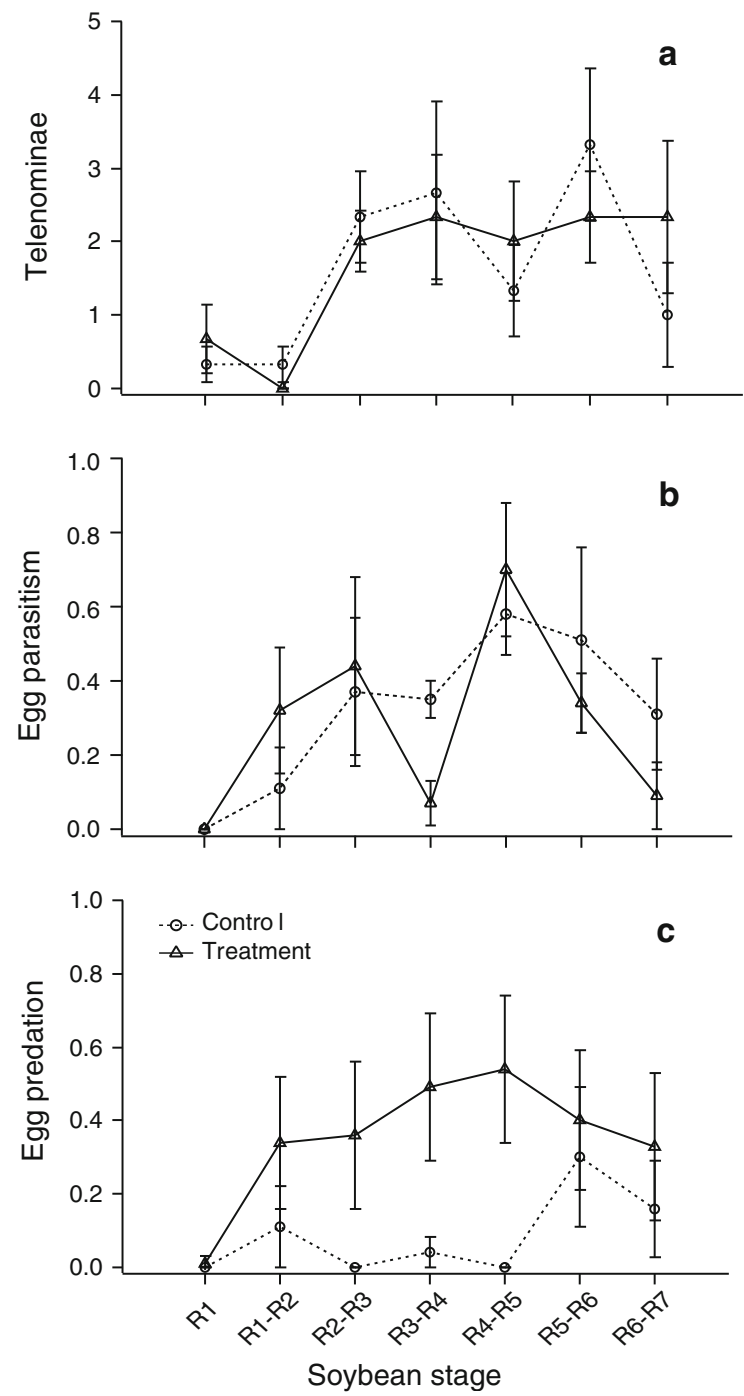

Fig. 3 Influence of treatment with (E)-2-hexenal on weekly variation of (a) mean abundance $( \pm \mathrm{SE})$ of parasitoids (Telenominae) captured with yellow sticky traps, (b) mean proportion of parasitism $( \pm \mathrm{SE})$ and $(\mathbf{c})$ mean proportion of predation $( \pm \mathrm{SE})$ on stink bug sentinel eggs glued on cardboards, by reproductive stage of soybean (R1-R7), in cages during long-term experiments in 2008

Geocoridae). Sentinel eggs were parasitized mainly by T. podisi and sporadically by Trissolcus teretis (Johnson). The GLM showed no effect of treatment with (E)-2-hexenal on the incidence of parasitism in sentinel eggs $(z=-1.86, P=0.06)$. The GLMM analyses indicated no significant effect of $(E)-2-$ hexenal on the intensity of parasitism $(z=-0.09$, $P=0.93)$. Both the effects of week $(z=-12.25$, $P<0.001)$ and the interaction week by treatment
( $z=5.98, P<0.001$ ) were significant (Fig. 3b). On the other hand, the same analyses indicated a significant effect of $(E)$-2-hexenal on the intensity of predation $(z=-3.74, P<0.001)$, with higher values of predation in treated plots (control: $0.08 \pm 0.23$, treatment: $0.35 \pm 0.45$; mean preyed eggs by treatment). Both the effects of week $(z=-11.35$, $P<0.001)$ and the interaction week by treatment $(z=6.62, P<0.001)$ were significant (Fig. 3c).

\section{Discussion}

Our results suggest that $(E)$-2-hexenal is attractive only to Trissolcus spp. when applied during the R2 soybean stage in the field (Fig. $2 \mathrm{a}-\mathrm{b}$ ). In experiments along the entire soybean reproductive cycle, the applications of $(E)$-2-hexenal did not affect the abundance of free-ranging adult Telenominae parasitoids in the field (Fig. 3a). Considering all experiments, treatment with $(E)$-2-hexenal was associated with greater intensity of parasitism only in short-term experiments. The treatment with the chemical compound also played an important role on egg predation by natural enemies, which was significantly higher in treated areas in the first short-term and in the long-term experiment, showing an increment through time (Fig. 3c).

Previous laboratory studies demonstrated that $(E)$ 2-hexenal was able to modify the search pattern of $T$. podisi, but the same compound had no significant attraction effect on T. basalis (Laumann et al. 2009). However, another laboratory study demonstrated that this compound induced a prolonged antennation time on the latter (Mattiacci et al. 1993). In our study, T. basalis, but not $T$. podisi, was attracted to $(E)$-2hexenal in short-term field experiments. Laboratory two-choice behavioral assays with single compounds or simplified mixtures of semiochemicals can provide evidence of volatiles attractant to parasitoids, but they are not necessarily equivalent to field experiment responses due to entangled and stochastic natural processes. The complexity of volatiles in the latter situation might lead insects to use background odor as a contrast to obtain information from specific chemicals. Therefore, a specific odor coding can be reached considering the quantity and quality of chemical mixtures that the parasitoid perceived (Hilker and McNeil 2008). 
The divergent responses observed between parasitoid species could be related to their favorite host (Corrêa-Ferreira 2002; Peres 2004). Although both species are generalist egg parasitoids, they showed differential host preferences, with $T$. podisi preferring E. heros and T. basalis preferring $N$. viridula as hosts (Peres 2004; Sujii et al. 2002). This suggests that each parasitoid has a different behavior in response to $(E)$ 2-hexenal, and a possible reason could be related to quantitative differences in the composition and proportion of secretion of metathoracic gland volatiles observed between preferred stink bugs species (Pareja et al. 2007). (E)-2-hexenal is the main component of metathoracic glands secretions of $N$. viridula $(\mathrm{McPh}-$ erson and McPherson 2000; Moraes et al. 2008a), a favorite host of T. basalis (Sujii et al. 2002). Euschistus heros is the dominant species of the soybean stink bug guild in central Brazil, whereas T. podisi is the dominant egg parasitoid species (Medeiros et al. 1997; 1998). This pattern was confirmed in this study, given the prevalence of $T$. podisi in the samples.

Previous field experiments in areas where T. basalis and its favorite host are dominant (southern Brazil) showed that parasitism in eggs of different stink bugs species was increased with $(E)$-2-hexenal $(5 \mathrm{mg}$ per septum) alone and with a mixture of $(E)$-2-hexenal and $n$-tridecane, another major component of metathoracic glands of different stink bug species (Baker et al. 1987; Pareja et al. 2007), in a dosage of $2.5 \mathrm{mg}$ per septum of each compound, when applied during the reproductive stage of soybean plants (Peres 2004). A similar response was observed when lacewings were monitored with a combination of methyl salicylate and the male aggregation pheromone iridodial (Jones et al. 2011). The results of our short-term experiments seemingly imply a convergent attraction effect of $(E)$ 2-hexenal on $T$. basalis. They suggest that the composition of the parasitoid guild and their specific responses to semiochemicals need to be considered for the efficient behavior manipulation of these parasitoids. In addition, a combination of plant volatiles and other compounds can increase the efficiency of semiochemicals in the field.

(E)-2-hexenal has been reported as stink bug's defensive compound (Aldrich 1988), alarm pheromone (Ishiwatari 1974; Lockwood and Story 1985; 1987) and nymph aggregation pheromone (Ishiwatari 1976; Lockwood and Story 1985), it is also a common green leaf volatile produced by soybean when subjected to stink bugs injuries (Michereff et al. 2011; Moraes et al. 2008a). As such, this compound can act as a long-range cue that allows parasitoids and also other natural enemies to find their host habitat, rather than a cue directly associated to their hosts in the field (Moraes et al. 2008a).

The observed influence of (E)-2-hexenal applications on egg predation is in agreement with other studies that found significant increment on the abundance of insect predators in areas treated with synthetic plant volatiles (James 2003, 2005; Simpson et al. 2011a). Future studies are necessary to investigate this matter in soybean thoroughly.

Our experiments indicated that the field application of $(E)$-2-hexenal had no effect on parasitism rates. In addition, parasitism rates were lower than those commonly found in soybean fields in southern (Corrêa-Ferreira and Moscardi 1995) and central-western Brazil (Medeiros et al. 1997; 1998). These results may stem from parasitoids species-specific responses to (E)-2-hexenal, from parasitoids host preferences and their density in the field, as previously stated.

The inverse relation between predation and parasitism observed in the first and third experiment (i.e. in areas where predation was high the parasitism tended to be low and vice versa) can be indicative of local density-dependent interactions and might have affected the results of egg parasitism, independently of treatment. Detailed exploration aiming to detect density-dependent interactions should be carefully studied in the future, because in certain host-parasitoid interactions the level of parasitism is dependent on host's density for a given spatial scale (Cronin and Strong 1990; Hassell 1985; Hassell and Waage 1984; Stiling 1987).

The absence of other stimuli used by parasitoids in their sequential behavior during host searching (Fatouros et al. 2008) can also contribute to the neutral effect of $(E)$-2-hexenal application on parasitism rates. When searching for hosts, Telenominae use different stimuli at long and short distances, such as synomones from plants (Colazza et al. 2014; Moraes et al. 2008b), chemicals left by stink bug foot prints (Borges et al. 2003), host vibratory signals (Laumann et al. 2011) and visual cues (de Aquino et al. 2012). The use of a single stimulus to attract parasitoids may not be effective for promoting both the recruitment of parasitoids and the increasing of parasitism in treated areas (Vieira et al. 2013). Further, parasitoid 
recruitment may not be directly linked to higher parasitism rates because their performance can be influenced by other ecological factors, such as presence of additional resources, food or even shelter (Moraes et al. 2013). Strategies as "attract-andreward" (Khan et al. 2008; Simpson et al. 2011b) or "push-pull" systems (Cook et al. 2007; Khan et al. 2011), which combine semiochemicals with vegetation diversity, could improve the action of natural enemies.

The lack of influence of $(E)$-2-hexenal upon parasitoid abundance during the long-term experiment was not expected, but the short distance between treated and control cages combined with the high spread action of this volatile compound might have invalidate the response of parasitoids. It is possible that the distance among cages $(20 \mathrm{~m})$ was not enough to show a clear effect of the compound during the long-term experiment and to avoid the inducible emission of volatiles from neighbor plants, as shown for some green leaf volatiles (Dudareva et al. 2006). The effective action distance for HIPVs and other semiochemicals to attract parasitoids or predators is largely unknown (Kaplan 2012). Some studies reports that effective distance to attract predators and parasitoids could vary between $1 \mathrm{~m}$ (Simpson et al. 2011a) to $10 \mathrm{~m}$ (Lee 2010). Additionally, time, dosage, release form (dispensers, sprays, plants emitting semiochemicals) and frequency of applications must also be considered (Kaplan 2012; Moraes et al. 2013). Also, the lack of effect of $(E)$-2-hexenal observed in our long-term experiment could be related to plant phenology or climatic seasonal variations. Simpson et al. (2011a) sprayed different HIPVs in vineyards, but only observed significant attraction of natural enemies in the early season application. Similarly, Vieira et al. (2013) found significant attraction in soybean plots sprayed with cis-jasmone only in the first four weeks after one application and no influence of the applications on parasitism levels.

Our results indicate the potential of $(E)$-2-hexenal to management of the egg parasitoid T. basalis and perhaps other natural enemies. Nevertheless, for an efficient use in the field, i.e. increased parasitism due to increased density of adult parasitoids, some open questions remain to be addressed, such as effective dosage, timing of application, and the combined use with other semiochemicals or with key plants to an "attract-and-reward" strategy. In addition, the effects of field applications of (E)-2-hexenal on stink bugs behavior also needs to be addressed, because this compound is usually found in their defensive gland secretion (Moraes et al. 2008a; Pareja et al. 2007), suggesting a biological function that is not yet described. To understand the effects of this compound on parasitoids populations in field conditions is important because these natural enemies drive the mortality of stink bugs in the early stage of development (eggs), contributing to the reduction of population levels of relevant pests in plants of agricultural importance.

Acknowledgments We thank Conselho Nacional de Desenvolvimento Científico e Tecnológico - CNPq (process \# 480501/2008-4), Empresa Brasileira de Pesquisa Agropecuária - Embrapa (process \# 03.07.5.100) and Fundação de Apoio à Pesquisa do Distrito Federal - FAPDF (process \# 193.000.469/ 2008) for funding. We thank Guarino Colli and James Pitts for comments and suggestions on earlier versions of the manuscript and Hélio Moreira dos Santos for his help with fieldwork. CRV thanks $\mathrm{CNPq}$ for providing a dissertation fellowship (process \#131208/2008-0).

\section{References}

Aldrich JR (1988) Chemical ecology of the Heteroptera. Annu Rev Entomol 33:211-238

Aldrich JR, Rosi MC, Bin F (1995) Behavioral correlates for minor volatile compounds from stink bugs (Heteroptera: Pentatomidae). J Chem Ecol 21:1907-1920

Baker R, Borges M, Cooke NG, Herbert RH (1987) Identification and synthesis of $(Z)-\left(1^{\prime} S, 3^{\prime} R, 4^{\prime} S\right)(-)-2-\left(3^{\prime}, 4^{\prime}\right.$-Epoxy$4^{\prime}$-methylcyclohexyl)-6-methylhepta-2,5-diene, the sex pheromone of the southern green stinkbug, Nezara viridula (L.). J Chem Soc Chem Comm 6:414-416

Bates D, Maechler M, Bolker B, Walker S (2013) lme4: linear mixed-effects models using Eigen and S4. R package version 1.0-5

Borges M, Aldrich JR (1994) Estudos de semioquímicos para o manejo de Telenominae, insetos benéficos. Ann Soc Entomol Brasil 23:575-577

Borges M, Costa MLM, Sujii ER, Cavalcanti MDG, Redigolo GF, Resck IS, Vilela EF (1999) Semiochemical and physical stimuli involved in host recognition by Telenomus podisi (Hymenoptera: Scelionidae) toward Euschistus heros (Heteroptera: Pentatomidae). Physiol Entomol 24:227-233

Borges M, Colazza S, Ramirez-Lucas P, Chauhan KR, Moraes MCB, Aldrich JR (2003) Kairomonal effect of walking traces from Euschistus heros (Heteroptera: Pentatomidae) on two strains of Telenomus podisi (Hymenoptera: Scelionidae). Physiol Entomol 28:349-355

Colazza S, Salerno G, Wajnberg E (1999) Volatile and contact chemicals released by Nezara viridula (Heteroptera: Pentatomidae) have a kairomonal effect on the egg 
parasitoid Trissolcus basalis (Hymenoptera: Scelionidae). Biol Control 16:310-317

Colazza S, McElfresh JS, Millar JG (2004) Identification of volatile synomones, induced by Nezara viridula feeding and oviposition on bean spp., that attract the egg parasitoid Trissolcus basalis. J Chem Ecol 30:945-964

Colazza S, Cusumano A, Lo Giudice D, Peri E (2014) Chemoorientation responses in hymenopteran parasitoids induced by substrate-borne semiochemicals. BioControl 59:1-17

Conti E, Salerno G, Bin F, Williams HJ, Vinson SB (2003) Chemical cues from Murgantia histrionica eliciting host location and recognition in the egg parasitoid Trissolcus brochymenae. J Chem Ecol 29:115-130

Cook SM, Khan ZR, Pickett JA (2007) The use of push-pull strategies in integrated pest management. Annu Rev Entomol 52:375-400

Corrêa-Ferreira BS (2002) Trissolcus basalis para o controle de percevejos da soja. In: Parra JRP, Botelho PSM, CorrêaFerreira BS, Bento JMS (eds) Controle biológico no Brasil: Parasitóides e Predadores. Manole, São Paulo, Brazil, pp 449-476

Corrêa-Ferreira BS, Moscardi F (1995) Seasonal occurrence and host spectrum of egg parasitoids associated with soybean stink bugs. Biol Control 5:196-202

Corrêa-Ferreira BS, Moscardi F (1996) Biological control of soybean stink bugs by inoculative releases of Trissolcus basalis. Entomol Exp Appl 79:1-7

Costa MLM, Borges M, Vilela EF (1998) Biologia reprodutiva de Euschistus heros (F.) (Heteroptera: Pentatomidae). An. Soc. Entomol. Bras. 27:559-568

Crawley MJ (2012) The R book, 2nd edn. John Wiley \& Sons Ltd, Chichester, UK

Cronin JT, Strong DR (1990) Density-independent parasitism among host patches by Anagrus delicatus (Hymenoptera, Mymaridae) - experimental manipulation of hosts. J Anim Ecol 59:1019-1026

de Aquino MFS, Dias AM, Borges M, Moraes MCB, Laumann RA (2012) Influence of visual cues on host-searching and learning behaviour of the egg parasitoids Telenomus podisi and Trissolcus basalis. Entomol Exp Appl 145:162-174

Demidenko E (2013) Mixed models: theory and applications with R, 2nd edn. Wiley, New Jersey, USA

Dudareva N, Negre F, Nagegowda DA, Orlova I (2006) Plant volatiles: recent advances and future perspectives. Crit Rev Plant Sci 25:417-440

Embrapa (2010) Tecnologias de Produção de Soja - Região Central do Brasil 2011. Embrapa Soja, Embrapa Cerrados, Embrapa Agropecuária Oeste, Londrina, Brazil

Fatouros NE, Dicke M, Mumm R, Meiners T, Hilker M (2008) Foraging behavior of egg parasitoids exploiting chemical information. Behav Ecol 19:677-689

Galecki A, Burzykowski T (2013) Linear mixed-effects models using R: a step-by-step approach. Springer, New York, USA

Hare JD (2011) Ecological role of volatiles produced by plants in response to damage by herbivorous insects. Annu Rev Entomol 56:161-180

Hassell MP (1985) Insect natural enemies as regulating factors. Ecology 54:323-334

Hassell MP, Waage JK (1984) Host-parasitoid population interactions. Annu Rev Entomol 29:89-114
Hilker M, McNeil JN (2008) Chemical and behavioral ecology in insect parasitoids: how to behave optimally in a complex odorous environment. In: Wajnberg E, Bernstein C, van Alphen J (eds) Behavioural ecology of insect parasitoids: from theoretical approaches to field applications. WileyBlackwell, London, UK, pp 92-112

Ishiwatari T (1974) Studies on the scent of stink bugs (Hemiptera: Pentatomidae). I. Alarm pheromone activity. Appl Entomol Zool 9:153-158

Ishiwatari T (1976) Studies on the scent of stink bugs (Hemiptera: Pentatomidae). II. Aggregation pheromone activity. Appl Entomol Zool 11:38-44

James DG (2003) Synthetic herbivore induced plant volatiles as field attractants for beneficial insects. Environ Entomol 32:977-982

James DG (2005) Further field evaluation of synthetic herbivore induced plant volatiles as attractants for beneficial insects. J Chem Ecol 31:481-495

Jones VP, Steffan SA, Wiman NG, Horton DR, Miliczky E, Zhang QH, Baker CC (2011) Evaluation of herbivoreinduced plant volatiles for monitoring green lacewings in Washington apple orchards. Biol Control 56:98-105

Kaplan I (2012) Attracting carnivorous arthropods with plant volatiles: the future of biocontrol or playing with fire? Biol Control 60:77-89

Khan ZR, Midega CAO, Amudavi DM, Hassanali A, Pickett JA (2008) On-farm evaluation of the 'push-pull' technology for the control of stemborers and striga weed on maize in western Kenya. Field Crop Res 106:224-233

Khan Z, Midega C, Pittchar J, Pickett J, Bruce T (2011) Pushpull technology: a conservation agriculture approach for integrated management of insect pests, weeds and soil health in Africa UK government's Foresight Food and Farming Futures project. Int J Agr Sustain 9:162-170

Laumann RA, Moraes MCB, Pareja M, Alarcão GC, Botelho AC, Maia ANH, Leonardecz-Neto E, Borges M (2008) Comparative biology and functional response of Trissolcus spp. (Hymenoptera: Scelionidae) and implications for stink-bugs (Hemiptera: Pentatomidae) biological control. Biol Control 44:32-41

Laumann RA, Aquino MFS, Moraes MCB, Pareja M, Borges M (2009) Response of the egg parasitoids Trissolcus basalis and Telenomus podisi to compounds from defensive secretions of stink bugs. J Chem Ecol 35:8-19

Laumann RA, Cokl A, Lopes APS, Ferreira JBC, Moraes MCB, Borges M (2011) Silent singers are not safe: selective response of a parasitoid to substrate-borne vibratory signals of stink bugs. Anim Behav 82:1175-1183

Lee JC (2010) Effect of methyl salicylate-based lures on beneficial and pest arthropods in strawberry. Environ Entomol 39:653-660

Lockwood JA, Story RN (1985) Bifunctional pheromone in the first instar of the southern green stink bug, Nezara viridula (L.) (Hemiptera: Pentatomidae): its characterization and interaction with other stimuli. Ann Entomol Soc Am 78:474-479

Lockwood JA, Story RN (1987) Defensive secretion of the southern green stink bug (Hemiptera: Pentatomidae) as an alarm pheromone. Ann Entomol Soc Am 80:686-691

Mattiacci L, Vinson SB, Williams HJ, Aldrich JR, Bin F (1993) A long-range attractant kairomone for egg parasitoid 
Trissolcus basalis, isolated from defensive secretion of its host, Nezara viridula. J Chem Ecol 19:1167-1181

McPherson JE, McPherson R (2000) Stink bugs of economic importance in America North of Mexico. CRC Press LLC, Florida, USA

Meats A, Pando MC (2002) Ratio-dependent parasitism with Trissolcus basalis (Wollaston) (Hymenoptera: Scelionidae) on egg rafts of Nezara viridula (Linnaeus) (Hemiptera: Pentatomidae): effect of experimental variables and compatibility of 'ratio' and 'Holling' models. Aust J Entomol 41:243-252

Medeiros MA, Schimidt FGV, Loiácono M, Carvalho VF (1997) Parasitismo e predação em ovos de Euschistus heros (Fab.) (Heteroptera: Pentatomidae) no Distrito Federal, Brasil. An Soc Entomol Bras 26:397-401

Medeiros MA, Loiácono M, Borges M, Schmidt FGV (1998) Incidência natural de parasitóides em ovos de percevejos (Hemiptera: Pentatomidae) encontrados na soja no Distrito Federal. Pesqui Agropecu Bras 33:1431-1435

Michereff MFF, Laumann RA, Borges M, Michereff M, Diniz IR, Neto ALF, Moraes MCB (2011) Volatiles mediating a plant-herbivore-natural enemy interaction in resistant and susceptible soybean cultivars. J Chem Ecol 37:273-285

Moraes MCB, Pareja M, Laumann RA, Borges M (2008a) The chemical volatiles (semiochemicals) produced by Neotropical stink bugs (Hemiptera: Pentatomidae). Neotrop Entomol 37:489-505

Moraes MCB, Pareja M, Laumann RA, Hoffmann-Campo CB, Borges M (2008b) Response of the parasitoid Telenomus podisi to induced volatiles from soybean damaged by stink bug herbivory and oviposition. J Plant Interact 3:111-118

Moraes MCB, Borges M, Laumann RA (2013) The application of chemical cues in arthropod pest management for arable crops. In: Wajnberg E, Colazza S (eds) Chemical ecology of insect parasitoids. Wiley-Blackwell, London, pp 225-244

Panizzi AR (1997) Wild hosts of pentatomids: ecological significance and role in their pest status on crops. Annu Rev Entomol 42:99-122

Pareja M, Borges M, Laumann RA, Moraes MCB (2007) Interand intraspecific variation in defensive compounds produced by five neotropical stink bug species (Hemiptera: Pentatomidae). J Insect Physiol 53:639-648

Peres WAA (2004) Aspectos bioecológicos e táticas de manejo dos percevejos Nezara viridula (Linnaeus), Euschistus heros (Fabricius) e Piezodorus guildinii (Westwood) (Hemiptera: Pentatomidae) em cultivo orgânico de soja. Departamento de Entomologia, Universidade Federal do Paraná, Curitiba, Brazil 160 pp

Pires CSS, Sujii ER, Borges M, Schmidt FGV, Zarbin PHG, Azevedo VCR, Lacerda AL, Pantaleão D (2001) Ação cairomonal de componentes do feromônio de alarme do percevejo verde pequeno da soja, Piezodorus guildinii, sobre o parasitóide de ovos Telenomus podisi. Embrapa Recursos Genéticos e Biotecnologia, Brasília, Brazil

Price PW, Bouton CE, Gross P, McPheron BA, Thompson JN, Weis AE (1980) Interactions among three trophic levels: Influence of plants on interactions between insect herbivores and natural enemies. Annu Rev Ecol Syst 11:41-65

Quinn GP, Keough MJ (2002) Experimental design and data analysis for biologists. Cambridge University Press, Cambridge, UK
R Development Core Team (2013) R: a language and environment for statistical computing: R Foundation for Statistical Computing. Vienna, Austria

Ritchie SW, Hanway JJ, Thompson HE (1988) How a soybean plant develops. Iowa State University of Science and Technology, Ames, USA

Silva CC, Moraes MCB, Laumann RA, Borges M (2006) Sensory response of the egg parasitoid Telenomus podisi to stimuli from the bug Euschistus heros. Pesqui Agropecu Bras 41:1093-1098

Simpson M, Gurr GM, Simmons AT, Wratten SD, James DG, Leeson G, Nicol HI (2011a) Insect attraction to synthetic herbivore-induced plant volatile-treated field crops. Agr Forest Entomol 13:45-57

Simpson M, Gurr GM, Simmons AT, Wratten SD, James DG, Leeson G, Nicol HI, Orre-Gordon GUS (2011b) Attract and reward: combining chemical ecology and habitat manipulation to enhance biological control in field crops. J Appl Ecol 48:580-590

Stiling PD (1987) The frequency of density dependence in insect host-parasitoid systems. Ecology 68:844-856

Straub CS, Finke DL, Snyder WE (2008) Are the conservation of natural enemy biodiversity and biological control compatible goals? Biol Control 45:225-237

Sujii ER, Costa MLM, Pires CSS, Colazza S, Borges M (2002) Inter and intra-guild interactions in egg parasitoid species of the soybean stink bug complex. Pesqui Agropecu Bras 37:1541-1549

Tabachnick BG, Fidell LS (2013) Using multivariate statistics, 6th edn. Allyn \& Bacon, Needham, USA

Tillman PG (2010) Parasitism and predation of stink bug (Heteroptera: Pentatomidae) eggs in Georgia corn fields. Environ Entomol 39:1184-1194

Vet LEM, Dicke M (1992) Ecology of infochemical use by natural enemies in a tritrophic context. Annu Rev Entomol 37:141-172

Vieira CR, Moraes MCB, Borges M, Sujii ER, Laumann RA (2013) cis-Jasmone indirect action on egg parasitoids (Hymenoptera: Scelionidae) and its application in biological control of soybean stink bugs (Hemiptera: Pentatomidae). Biol Control 64:75-82

Vinson SB, Bin F, Vet LEM (1998) Critical issues in host selection by insect parasitoids. Biol Control 11:77-78

Zuur AF, Ieno EN, Walker NJ, Saveliev AA, Smith GM (2009) Mixed effect models and extensions in ecology with R. Springer, New York, USA

Cecília Rodrigues Vieira is currently a graduate student in biology at Utah State University, USA, with interest in the ecology and biogeography of mutilid wasps.

Maria Carolina Blassioli Moraes is a researcher in the Laboratório de Semioquímicos, Embrapa, and is interested in plant semiochemicals and insect pheromones.

Miguel Borges is a researcher in Laboratório de Semioquímicos, Embrapa, and is interested in chemical ecology and behavior of insects. 
Carmen Silvia Soares Pires is a researcher in Laboratório de Ecologia, Embrapa, and is interested in biological control and other ecological services in crops.

Edison Ryoiti Sujii is a researcher in the Laboratório de Ecologia, Embrapa, and is interested in biological control and other ecological services in crops.
Raúl Alberto Laumann is a researcher in the Laboratório de Semioquímicos, Embrapa, and is interested in chemical ecology and behavior of insects, specially parasitoids. 